\title{
Assessment of pulmonary congestion is of prime importance
}

\author{
Go Hiasa $^{1} \cdot$ Hideki Okayama ${ }^{1} \cdot$ Yukio Kazatani $^{1}$
}

Received: 26 March 2019 / Accepted: 5 April 2019 / Published online: 9 April 2019

(c) Springer Japan KK, part of Springer Nature 2019

The authors reply:

It is well known that pulmonary congestion is a major predictor of morbidity and mortality in heart failure and is the single most important contributor to hospitalization, even more significant than low cardiac output [1]. Several studies reported that adaptive servo-ventilation (ASV) therapy improves cardiac output in patients with high-pulmonary capillary wedge pressure (PCWP), elevated $E / e^{\prime}$, and advanced mitral regurgitation $[2,3]$. These parameters indicate the presence of pulmonary congestion. The present study demonstrated that ASV therapy significantly reduced the degree of mitral regurgitation, accompanied by a tendency toward a decrease in $E / e^{\prime}$. Thus, ASV therapy was considered to contribute to the improvement of pulmonary congestion, resulting in reduction in readmissions and total medical costs in patients with chronic heart failure who had a history of repeated hospitalizations.

Although PCWP measured by right heart catheterization is considered the most reliable marker for the assessment of pulmonary congestion, it is difficult to study repeatedly because of the invasive measurement procedure. Thus, noninvasive and reliable tools for monitoring PCWP could replace the invasive approaches. Imamura and colleagues demonstrated that remote dielectric sensing (ReDS) technology can quantify lung fluid content noninvasively and identify PCWP of $\geq 18 \mathrm{mmHg}$ with high reliability [4, 5]. After publication of the SERVE-HF trial [6], the benefit and safety of ASV for HF patients who continue or initiate ASV therapy must be reconsidered. Non-invasive methods such as the ReDS technology are expected to be useful for identifying responders, setting the appropriate pressures of ASV, and judging the termination timing of ASV therapy.

Hideki Okayama

c-hokayama@eph.pref.ehime.jp

1 Department of Cardiology, Ehime Prefectural Central Hospital, 83 Kasuga-machi, Matsuyama, Ehime 790-0024, Japan

\section{References}

1. Gheorghiade M, Abraham WT, Albert NM, Greenberg BH, O'Connor CM, She L, Stough WG, Yancy CW, Young JB, Fonarow GC, OPTIMIZE-HF Investigators Coordinators (2006) Systolic blood pressure at admission, clinical characteristics, and outcomes in patients hospitalized with acute heart failure. JAMA 296:2217-2226

2. Haruki N, Takeuchi M, Kaku K, Yoshitani H, Kuwaki H, Tamura M, Abe H, Okazaki M, Tsutsumi A, Otsuji Y (2011) Comparison of acute and chronic impact of adaptive servo-ventilation on left chamber geometry and function in patients with chronic heart failure. Eur J Heart Fail 13:1140-1146

3. Yamada S, Sakakibara M, Yokota T, Kamiya K, Asakawa N, Iwano H, Yamada S, Oba K, Tsutsui H (2013) Acute hemodynamic effects of adaptive servo-ventilation in patients with heart failure. Circ J 77:1214-1220

4. Amir O, Azzam ZS, Gaspar T, Faranesh-Abboud S, Andria N, Burkhoff D, Abbo A, Abraham WT (2016) Validation of remote dielectric sensing (ReDS) technology for quantification of lung fluid status: Comparison to high resolution chest computed tomography in patients with and without acute heart failure. Int $\mathrm{J}$ Cardiol 221:841-846

5. Uriel N, Sayer G, Imamura T, Rodgers D, Kim G, Raikhelkar J, Sarswat N, Kalantari S, Chung B, Nguyen A, Burkhoff D, Abbo A (2018) Relationship between noninvasive assessment of lung fluid volume and invasively measured cardiac hemodynamics. J Am Heart Assoc 7(22):e009175

6. Cowie MR, Woehrle H, Wegscheider K, Angermann C, d'Ortho MP, Erdmann E, Levy P, Simonds AK, Somers VK, Zannad F, Teschler H (2015) Adaptive servo- ventilation for central sleep apnea in systolic heart failure. N Engl J Med 373:1095-1105

Publisher's Note Springer Nature remains neutral with regard to jurisdictional claims in published maps and institutional affiliations. 